\title{
End-tidal to arterial carbon dioxide gradient in traumatic brain injury after prehospital emergency anesthesia is associated with in-hospital mortality: a retrospective observational study
}

\section{Pascal Doppmann}

Kantonsspital St Gallen: Kantonsspital Sankt Gallen

\section{Lorenz Meuli}

University Hospital Zurich: UniversitatsSpital Zurich

\section{Stephen Sollid}

Norwegian Air Ambulance Foundation

Miodrag Filipovic

Kantonsspital St Gallen: Kantonsspital Sankt Gallen

Jürgen Knapp

Inselspital Bern Universitatsklinik fur Anasthesiologie und Schmerztherapie

\section{Aristomenis Exadaktylos}

Inselspital Universitatsspital Bern

\section{Roland Albrecht}

Kantonsspital St Gallen: Kantonsspital Sankt Gallen

Urs Pietsch ( $\square$ urs.pietsch@kssg.ch )

Kantonsspital Sankt Gallen https://orcid.org/0000-0001-6957-2638

\section{Research}

Keywords: HEMS, prehospital anesthesia, TBI, end-tidal to arterial carbon dioxide gradient

Posted Date: January 29th, 2021

DOI: https://doi.org/10.21203/rs.3.rs-157789/v1

License: (c) (1) This work is licensed under a Creative Commons Attribution 4.0 International License. Read Full License 


\section{Abstract}

Background Early definitive airway protection and normoventilation are key principles in the treatment of severe traumatic brain injury. These are currently guided by end tidal $\mathrm{CO}_{2}$ as a proxy for $\mathrm{PaCO}_{2}$. We assessed whether the difference between end tidal $\mathrm{CO}_{2}$ and $\mathrm{PaCO}_{2}$ at hospital admission is associated with in-hospital mortality.

Method We conducted a retrospective observational cohort study of consecutive patients with traumatic brain injury who were intubated and transported by Helicopter Emergency Medical Services to a Level 1 trauma center between January 2014 and December 2019. We assessed the association between the $\mathrm{CO}_{2}$ gap-defined as the difference between end tidal $\mathrm{CO}_{2}$ and $\mathrm{PaCO}_{2}$-and in-hospital mortality using multivariate logistic regression models.

Results 105 patients were included in this study. The mean \pm SD $\mathrm{CO}_{2}$ gap at admission was $1.64( \pm 1.09)$ $\mathrm{kPa}$ and significantly greater in non-survivors than survivors (2.26 $\pm 1.30 \mathrm{kPa}$ vs. $1.42 \pm 0.92 \mathrm{kPa}, \mathrm{p}<.001)$. The correlation between $\mathrm{EtCO}_{2}$ and $\mathrm{PaCO}_{2}$ at admission was low (Pearson's $\mathrm{r}=.287$ ). The mean $\mathrm{CO}_{2}$ gap after 24 hours was only $0.64 \pm 0.82 \mathrm{kPa}$, and no longer significantly different between non-survivors and survivors. The multivariate logistic regression model showed that the $\mathrm{CO}_{2}$ gap was independently associated with increased mortality in this cohort and associated with a 2.7-fold increased mortality for every $1 \mathrm{kPa}$ increase in the $\mathrm{CO}_{2}$ gap (OR 2.692, 95\% Cl 1.293 to $5.646, \mathrm{p}=.009$ ).

Conclusions This study demonstrates that the difference between $\mathrm{EtCO}_{2}$ and $\mathrm{PaCO}_{2}$ is significantly associated with in-hospital mortality in patients with traumatic brain injury. $\mathrm{EtCO}_{2}$ was significantly lower than $\mathrm{PaCO}_{2}$, making it an unreliable proxy for $\mathrm{PaCO}_{2}$ when aiming for normocapnic ventilation. The higher-than-expected $\mathrm{CO} 2$ gap will lead to iatrogenic hypoventilation when normocapnic ventilation is aimed at, and might thereby increase in-hospital mortality.

\section{Background}

Treatment recommendations in traumatic brain injury (TBI) include early definitive airway protection as well as normoventilation with a target arterial partial pressure of $\mathrm{CO}_{2}\left(\mathrm{PaCO}_{2}\right)$ of $4.6-5.9 \mathrm{kPa}$ (35 to 45 $\mathrm{mmHg})[1,2]$. The effects of hypo- or hyperventilation on cerebral blood flow (CBF), with the potential for hypoxemia or hyperemia of cerebral tissue and their negative impact on outcome, have been widely studied [3-7]. Using $\mathrm{PaCO}_{2}$ to monitor ventilation requires arterial blood gas (ABG) analyses, but the necessary lab equipment is not yet widely available in the prehospital environment. Therefore end-tidal $\mathrm{CO}_{2}\left(\mathrm{EtCO}_{2}\right)$ determined by capnography has been used as a surrogate marker to estimate $\mathrm{PaCO}_{2}$ assuming a reliable correlation between $\mathrm{EtCO}_{2}$ and $\mathrm{PaCO}_{2}$ [8].

Capnography is considered the gold standard, both to determine correct placement of a definitive airway and to guide ventilation during emergency care $[9,10]$. The assumed correlation between $\mathrm{EtCO}_{2}$ and 
$\mathrm{PaCO}_{2}$ has been known to be accompanied by a tension difference of $\mathrm{CO}_{2}$ ranging anywhere between 0.26 and $0.66 \mathrm{kPa}$ ( 2 and $5 \mathrm{mmHg}$ ) in otherwise healthy individuals undergoing anesthesia [11-16]. However, major trauma accompanying TBI can negatively influence ventilation and perfusion, making the interpolation of $\mathrm{PaCO}_{2}$ from $\mathrm{EtCO}_{2}$ in trauma patients unreliable [17-19]. As expected, subgroup analyses have shown the best correlation between $\mathrm{EtCO}_{2}$ and $\mathrm{PaCO}_{2}$ in isolated TBI when compared to other trauma patients [20].

The primary aim of this study is to describe the correlation between $\mathrm{EtCO}_{2}$ and $\mathrm{PaCO}_{2}$ at the time of admission in patients hospitalized with TBI. Furthermore, we investigated the predictive value of tension difference of $\mathrm{CO}_{2}$ between $\mathrm{EtCO}_{2}$ and $\mathrm{PaCO}_{2}\left(\mathrm{CO}_{2}\right.$ gap) for in-hospital mortality.

\section{Methods}

\section{Study participants, setting and ethics approval}

This retrospective observational single-center cohort study included all consecutive patients with TBI who were intubated on the scene and transported by the helicopter emergency medical service (HEMS) (Swiss Air-Rescue, Rega) to a Level 1 trauma center (Kantonsspital St. Gallen, Switzerland) between January 1st of 2014 and December 31 st of 2019. Exclusion criteria were patients who were not intubated before admission, patients with traumatic injuries requiring intubation for other reasons than $\mathrm{TB}$, and secondary transport missions including patients with traumatic brain injury who were transported from another hospital to this trauma center.

The local ethics committee of St. Gallen (EKOS) granted permission to use patient data without individual consent according to the federal act on research involving human beings and the ordinance on human research with the exception of clinical trials. The permission also covered the use of patient data regarding the HEMS operation (EKOS St. Gallen 7.7.2020, BASEC Nr. 2020-01737 EKOS 20/122).

\section{Data and definitions}

Baseline characteristics of patients were obtained from electronic hospital records. Laboratory findings were obtained by automated retrieval using the unique patient identification number in the hospital records. EtCO $\mathrm{Et}_{2}$ was measured using main-stream capnographs. Information on the ventilator settings at admission was prospectively entered into the patients' electronic hospital records.

Outcome information (i.e., survival status) was documented prospectively as part of the routine electronic hospital records and obtained from the corresponding record.

The Injury Severity Score Thorax was determined at admission. $\mathrm{EtCO}_{2}$, systolic blood pressure, pulse and $\mathrm{SpO}_{2}$ were analyzed on admission to the Emergency Room (ER) as well as 24 hours after admission.

\section{Statistics}


Patients' characteristics were summarized and presented in tables. Continuous variables were summarized by mean \pm SD (standard deviation) if normally distributed or by median and IQR (interquartile range) if skewed. Normality was tested using the Shapiro-Wilk test. Categorical variables were summarized with counts and percentages for each level of the variable. Outliers were assessed using the Grubbs test for continuous variables if normally distributed.

Correlation between $\mathrm{EtCO}_{2}$ and $\mathrm{PaCO}_{2}$ was assessed using Pearson's correlation coefficient and visualized using a scatter plot. Disagreement between $\mathrm{EtCO}_{2}$ and $\mathrm{PaCO}_{2}$ was visualized using a BlandAltman plot [21]. Differences in the $\mathrm{CO}_{2}$ gap between survivors and non-survivors were tested using the Mann-Whitney-Wilcoxon Test. The association between the $\mathrm{CO}_{2}$ gap and the in-hospital mortality was further assessed using a multivariable logistic regression model. To minimize confounding, variables potentially associated with the respiratory system and in-hospital mortality were defined a priori based on a literature review and clinical experience [22]. The variables included age, heart rate, systolic blood pressure, peripheral capillary oxygen saturation, pressure of oxygen in arterial blood (paO2), and severity of chest injury documented by the ISS (Injury Severity Score) thoracic sub-score. All variables were coded as continuous variables. Complete case analyses were performed due to the low number of missing data and therefore the low risk of bias. As a sensitivity analysis, the association of the time difference between the initial arterial blood gas sample and the first recorded $\mathrm{EtCO}_{2}$ was explored using a univariate linear regression model.

Two-sided $p$-values of $<0.05$ were considered as statistically significant. All statistical analyses were performed using R Studio 3.6.0 on macOS 10.15.7.

\section{Results}

This study adheres to the STROBE Statement (Strengthening the Reporting of Observational Studies in Epidemiology) [23]. From January 2014 to December 2019 a total of 181 patients were admitted to our trauma center by HEMS after TBI and intubation. Seventy-six patients were excluded. Reasons were mechanisms of injury besides $\mathrm{TBI}$, an alternate reason for unconsciousness, missing ISS, $\mathrm{EtCO}_{2}$ or $\mathrm{PaCO}_{2}$ data, or early extubation in the ER.

Of the 105 patients admitted to the ICU, 28 (27\%) died and 77 (73\%) were discharged alive. Information on neurological function at discharge was not available.

The patients' baseline characteristics are displayed in Table 1. Of note, non-survivors were on average more than 20 years older than survivors and had a lower $\mathrm{PaO}_{2}$ in the initial blood gas samples, $\mathrm{p}<0.001$.

The correlation between $\mathrm{EtCO}_{2}$ and $\mathrm{PaCO}_{2}$ at admission was low, Pearson's $\mathrm{r}=.287$, Figure 1. There was a significant difference between $\mathrm{EtCO}_{2}$ and $\mathrm{PaCO}_{2}$ at admission. The overall mean $\mathrm{CO}_{2}$ gap at admission was $1.64 \pm 1.09 \mathrm{kPa}$ and significantly larger in non-survivors than survivors, $2.26 \pm 1.30 \mathrm{kPa}$ vs. $1.42 \pm 0.92$ $\mathrm{kPa}, \mathrm{p}<.001$, see Table 2 and Figure 2. Of note, the $\mathrm{CO}_{2}$ gap (visualized as mean bias on the Bland-Altman 
plots) was more pronounced in patients with lower $\mathrm{EtCO}_{2}$ values. This demonstrates that patients with $\mathrm{EtCO}_{2}$ measures within the target range (4.6 to $5.9 \mathrm{kPa}$ ) were unwittingly hypercapnic [1,2]. The overall $\mathrm{CO}_{2}$ gap decreased to $0.64 \pm 0.82 \mathrm{kPa}$ at $24 \mathrm{~h}$ after admission and was no longer significantly different between non-survivors and survivors, $0.78 \pm 0.70 \mathrm{kPa}$ vs. $0.58 \pm 0.86, p=.108$, see Table 2 and Figure 2 .

The multivariate logistic regression model showed that the $\mathrm{CO}_{2}$ gap was independently associated with increased mortality in intubated and mechanically ventilated patients with TBI. For every increase of the $\mathrm{CO}_{2}$ gap by $1 \mathrm{kPa}$, mortality was 2.7 times higher, OR 2.692, 95\%-Cl 1.293 to $5.646, \mathrm{p}=.009$. Higher age was independently associated with an increased mortality rate as well, OR 1.842 for every increase of 10 years, $95 \% \mathrm{Cl} 1.106$ to $2.641, \mathrm{p}=.001$. Systolic blood pressure, heart rate, thoracic trauma, $\mathrm{SpO}_{2}$ and $\mathrm{PaO}_{2}$ were not associated with survival status in this multivariate model, see Table 3 and Figure 4. Inclusion of further parameters from the arterial blood gas samples (ABG samples), the total ISS, or other cardiopulmonary parameters in the regression model led to multicollinearity; these parameters were therefore excluded from the final model.

The majority of $\mathrm{EtCO}_{2}$ and $\mathrm{PaCO}_{2}$ pairs were obtained within 30 minutes, $\mathrm{n}=60,57 \%$. As a sensitivity analysis the impact of the time interval between arterial blood gas sampling and the documentation of $\mathrm{EtCO}_{2}$ from monitors on the $\mathrm{CO}_{2}$ gap was assessed in a univariate linear regression model. This association was not significant, $p=.165$.

\section{Discussion}

Our results show that end-tidal capnography is an unreliable tool for monitoring and targeting invasive ventilation at least in the initial treatment of patients with severe TBI. Although the majority of the patients in this study were ventilated within the target range of $\mathrm{EtCO}_{2}$ values, many were unwittingly hypercapnic in the first blood gas sample after arriving in the hospital. Our data show a large variability in the calculated $\mathrm{CO}_{2}$ gap in this patient cohort and it was more pronounced in patients with lower $\mathrm{EtCO}_{2}$. This underestimation of $\mathrm{PaCO}_{2}$ when $\mathrm{EtCO}_{2}$ was used to guide ventilation caused hypoventilation despite normal $\mathrm{EtCO}_{2}$ values. An increased $\mathrm{CO}_{2}$ gap and the resulting hypercapnia were associated with increased in-hospital mortality. This underlines the clinical importance of these findings and the need for either a more reliable surrogate parameter for $\mathrm{PaCO}_{2}$ estimation or early $\mathrm{PaCO}_{2}$ sampling in the prehospital management of patients with TBI.

\section{The $\mathrm{CO}_{2}$ gap}

Previous studies have observed that the $\mathrm{CO}_{2}$ gap is multifactorial, with possible causes including ventilation-perfusion mismatch, increased dead space, or, shock with impaired perfusion and temperature $[11,24]$. However, most of these factors influencing the $\mathrm{CO}_{2}$ gap are not measurable, detectable or predictable in the initial treatment period in the field or ER. The ability to predict or gauge the $\mathrm{CO}_{2}$ gap based on the patient's condition is consequently limited. In this context the $\mathrm{CO}_{2}$ gap might be both, an 
indicator of severity of injury, and a predictor of impaired survival in patients with severe traumatic brain injury.

Two recent publications investigated the $\mathrm{CO}_{2}$ gap in critically ill patients after prehospital emergency anesthesia $[25,26]$. Their findings are in line with our results and showed only moderate correlation between $\mathrm{EtCO}_{2}$ and $\mathrm{PaCO}_{2}$, confirming that $\mathrm{EtCO}_{2}$ alone should be used with caution to guide ventilation in the critically ill.

In a cohort of cardiac arrest patients, Suominen et al. showed an association between an increased $\mathrm{CO}_{2}$ gap and in-hospital mortality 24 hours after return of spontaneous circulation (ROSC). Our data is in line with these findings and reinforces the plausibility of this association by controlling for potential confounding due to shock or hypoperfusion in a multivariate logistic regression model.

\section{$\mathrm{EtCO}_{2}$ as a surrogate marker}

$\mathrm{PaCO}_{2}$ is considered to be the major determinant of cerebral blood flow (CBF) through its effects on cerebral vascular tone [27]. This reinforces the importance of precise ventilatory control in the initial management of TBI. It is known that even modest hypercapnia can result in substantial increases in ICP and can cause dangerous cerebral ischemia when intracranial compliance is poor [28]. Therefore, we hypothesize that the hypoventilation due to underestimation of the arterial $\mathrm{CO}_{2}$ using $\mathrm{EtCO}_{2}$ as a surrogate marker leads to impaired CBF and thereby increases mortality.

Recent TBI guidelines rely on the assumption that the $\mathrm{CO}_{2}$ gap is approximately $0.5 \mathrm{kPa}(3.8 \mathrm{mmHg})$. However, these assumptions are based on data of individuals undergoing general anesthesia without major comorbidities or trauma $[11,29]$. In this study, the mean first $\mathrm{EtCO}_{2}$ was $4.6 \pm 0.78 \mathrm{kPa}$, whereas the mean $\mathrm{PaCO}_{2}$ was $6.26 \pm 1.03 \mathrm{kPa}$ and far in excess of the target of 4.5 to $5.0 \mathrm{kPa}$. Therefore, relying on $\mathrm{EtCO}_{2}$ as a surrogate for $\mathrm{PaCO}_{2}$ provides a false sense of security, and providers may not achieve optimal prehospital $\mathrm{PaCO}_{2}$. At present, no reliable alternative to direct $\mathrm{ABG}$ sampling seems to exist in order to approximate $\mathrm{PaCO}_{2}$ reliably.

However, to our best knowledge, there is no data supporting the routine use of point-of-care blood gas analyses in patients mechanically ventilated in the field. This lack of data could be due to the fact that up to now the importance of point-of-care testing in prehospital care has been underestimated, due to the high reliance on proxy markers like $\mathrm{EtCO}_{2}$. Further studies on the optimal timing of sampling after intubation and the beginning of mechanical ventilation, as well as the optimal sampling interval, are needed. We postulate that a single ABG sample post-intubation could gauge the individual $\mathrm{CO}_{2}$ gap and ensure more reliable $\mathrm{EtCO}_{2}$-guided ventilation.

\section{Factors influencing mortality}


Our data showed a significant age difference between survivors and non-survivors. Age was

independently and significantly associated with mortality. Besides the fact that age might be a surrogate for unrecognized confounders due to comorbidities that negatively influence mortality, clinical decisionmaking may also play a role. In daily routine, palliation might be considered at an earlier stage in elderly trauma victims with limited rehabilitation potential, whereas younger trauma patients may receive maximum therapeutic interventions [30].

In our cohort, systolic blood pressure and ISS thorax scores were not significantly associated with mortality in the multivariate analysis.

\section{Limitations}

This study had several limitations. First, it is a retrospective and single-center cohort study with a limited sample size. However, data was almost complete and multivariate adjustments were performed. Second, in order to increase the number of eligible patients in this study, we included patients who had an ABG sample up to $30 \mathrm{~min}$ after hospital arrival. However, a sensitivity analysis showed that the observed gradient between $\mathrm{EtCO}_{2}$ and $\mathrm{PaCO}_{2}$ was not significantly associated with the time between arterial blood gas sampling and the documented $\mathrm{EtCO}_{2}$. Still, it is possible that a proportion of the gradient between $\mathrm{EtCO}_{2}$ and $\mathrm{PaCO}_{2}$ was due to changes in ventilation settings during this period.

\section{Conclusions}

The $\mathrm{CO}_{2}$ gap is an inconsistent phenomenon in pre-hospital anesthetized TBI patients, making $\mathrm{EtCO}_{2}$ an unreliable proxy for $\mathrm{PaCO}_{2}$ when aiming for normocapnic ventilation. The higher-than-expected $\mathrm{CO}_{2}$ gap can lead to unaware iatrogenic hypoventilation and consequently hypercapnia, which is associated with increased in-hospital mortality.

\section{Declarations}

\section{Ethics approval and consent to participate}

The local ethics committee of St. Gallen (EKOS) granted permission to use patient data without individual consent according to the federal act on research involving human beings and the ordinance on human research with the exception of clinical trials. The permission also covered the use of patient data regarding the HEMS operation (EKOS St. Gallen 7.7.2020, BASEC Nr. 2020-01737 EKOS 20/122).

\section{Consent for publication}

Consent for publication was waived as per the ethics approval.

\section{Availability of data and materials}


The datasets used and/or analyzed during the current study are available from the corresponding author on reasonable request.

\section{Competing interests}

The authors declare that they have no competing interests

\section{Funding}

The authors received no financial support for the research, authorship, and/or publication of this article.

\section{Authors' contributions}

UP, LM and PD designed the study. PD and UP performed Data collection. LM performed statistical analysis. UP, LM and PD drafted and finalized the manuscript. SJS, MF, JK, AE and RA reviewed the manuscript. All authors read and approved the final version of the manuscript.

\section{Acknowledgements}

The authors would like to thank Patrick Münger for assistance in acquiring data from the electronic hospital records, Qendi Marku for assistance in acquiring outcome data from electronic hospital records, Mario Tissi and Marlis Planzer for assistance in acquiring data from the HEMS Database and Jeannie Wurz for careful editing of the manuscript.

\section{References}

1. Abdelmalik PA, Draghic N, Ling GSF. Management of moderate and severe traumatic brain injury. Transfusion. 2019;59:1529-38.

2. Volovici V, Steyerberg EW, Cnossen MC, Haitsma IK, Dirven CMF, Maas AIR, et al. Evolution of Evidence and Guideline Recommendations for the Medical Management of Severe Traumatic Brain Injury. J Neurotrauma. 2019;36:3183-9.

3. Muizelaar JP, Marmarou A, Ward JD, Kontos HA, Choi SC, Becker DP, et al. Adverse effects of prolonged hyperventilation in patients with severe head injury: A randomized clinical trial. $\mathrm{J}$ Neurosurg. 1991;75:731-9.

4. Bouma GJ, Muizelaar JP. Cerebral blood flow, cerebral blood volume, and cerebrovascular reactivity after severe head injury. J Neurotrauma. United States; 1992;9 Suppl 1:S333-48.

5. Bouma GJ, Muizelaar JP. Cerebral blood flow in severe clinical head injury. New Horiz. United States; 1995;3:384-94.

6. Stein NR, McArthur DL, Etchepare M, Vespa PM. Early cerebral metabolic crisis after TBI influences outcome despite adequate hemodynamic resuscitation. Neurocrit Care. 2012;17:49-57.

7. Davis DP, Idris AH, Sise MJ, Kennedy F, Eastman AB, Velky T, et al. Early ventilation and outcome in patients with moderate to severe traumatic brain injury. Crit Care Med [Internet]. Crit Care Med; 2006 
[cited 2020 Dec 22];34:1202-8. Available from: https://pubmed.ncbi.nlm.nih.gov/16484927/

8. Maeda T, Yoshino A, Katayama Y. Guidelines for the management of severe traumatic brain injury: Updated in 2013. Japanese J Neurosurg. 2013;22:831-6.

9. Frerk C, Mitchell VS, McNarry AF, Mendonca C, Bhagrath R, Patel A, et al. Difficult Airway Society 2015 guidelines for management of unanticipated difficult intubation in adults. $\mathrm{Br} \mathrm{J}$ Anaesth. 2015;115:827-48.

10. Checketts MR. AAGBI recommendations for standards of monitoring during anaesthesia and recovery 2015. Anaesthesia. 2016;71:470-1.

11. Fletcher R, Jonson B. Deadspace and the single breath test for carbon dioxide during anaesthesia and artificial ventilation: Effects of tidal volume and frequency of respiration. $\mathrm{Br} \mathrm{J}$ Anaesth [Internet]. British Journal of Anaesthesia; 1984;56:109-19. Available from:

http://dx.doi.org/10.1093/bja/56.2.109

12. Fujimoto S, Suzuki M, Sakamoto K, Ibusuki R, Tamura K, Shiozawa A, et al. Comparison of end-tidal, arterial, venous, and transcutaneous pco2. Respir Care. 2019;64:1208-14.

13. Shankar KB, Moseley H, Vemula V, Ramasamy M, Kumar Y. Arterial to end-tidal carbon dioxide tension difference during anaesthesia in early pregnancy. Can J Anaesth. 1989;36:124-7.

14. Onodi C, Bühler PK, Thomas J, Schmitz A, Weiss M. Arterial to end-tidal carbon dioxide difference in children undergoing mechanical ventilation of the lungs during general anaesthesia. Anaesthesia. 2017;72:1357-64.

15. Hiller J, Silvers A, Mcllroy DR, Niggemeyer L, White S. A retrospective observational study examining the admission arterial to end-tidal carbon dioxide gradient in intubated major trauma patients. Anaesth Intensive Care. 2010;38:302-6.

16. Law GTS, Wong CY, Kwan CW, Wong KY, Wong FP, Tse HN. Concordance between side-stream endtidal carbon dioxide and arterial carbon dioxide partial pressure in respiratory service setting. Hong Kong Med J. 2009;15:440-6.

17. Yosefy C, Hay E, Nasri Y, Magen E, Reisin L. End tidal carbon dioxide as a predictor of the arterial PCO2 in the emergency department setting. Emerg Med J. 2004;21:557-9.

18. Belpomme V, Ricard-Hibon A, Devoir C, Dileseigres S, Devaud M-L, Chollet C, et al. Correlation of arterial PCO2 and PETCO2 in prehospital controlled ventilation. Am J Emerg Med. United States; 2005;23:852-9.

19. Prause G, Hetz H, Lauda P, Pojer H, Smolle-Juettner F, Smolle J. A comparison of the end-tidal-CO2 documented by capnometry and the arterial pCO2 in emergency patients. Resuscitation. Ireland; 1997;35:145-8.

20. Warner KJ, Cuschieri J, Garland B, Carlbom D, Baker D, Copass MK, et al. The utility of early end-tidal capnography in monitoring ventilation status after severe injury. J Trauma - Inj Infect Crit Care. 2009;66:26-31.

21. Martin Bland J, Altman DG. STATISTICAL METHODS FOR ASSESSING AGREEMENT BETWEEN TWO METHODS OF CLINICAL MEASUREMENT. Lancet. Elsevier; 1986;327:307-10. 
22. Yang JT, Erickson SL, Killien EY, Mills B, Lele A V., Vavilala MS. Agreement Between Arterial Carbon Dioxide Levels With End-Tidal Carbon Dioxide Levels and Associated Factors in Children Hospitalized With Traumatic Brain Injury. JAMA Netw open [Internet]. NLM (Medline); 2019 [cited 2020 Dec 11];2:e199448. Available from: https://jamanetwork.com/

23. von Elm E, Altman DG, Egger M, Pocock SJ, Gøtzsche PC, Vandenbroucke JP. The Strengthening the Reporting of Observational Studies in Epidemiology (STROBE) statement: guidelines for reporting observational studies. Lancet [Internet]. Elsevier; 2007 [cited 2020 Dec 11];370:1453-7. Available from: www.plosmedicine.org

24. Suominen PK, Stayer S, Wang W, Chang AC. The effect of temperature correction of blood gas values on the accuracy of end-tidal carbon dioxide monitoring in children after cardiac surgery. ASAIO J [Internet]. ASAIO J; 2007 [cited 2020 Dec 11];53:670-4. Available from: https://pubmed.ncbi.nlm.nih.gov/18043144/

25. Price J, Sandbach DD, Ercole A, Wilson A, Barnard EBG. End-tidal and arterial carbon dioxide gradient in serious traumatic brain injury after prehospital emergency anaesthesia: a retrospective observational study. Emerg Med J. 2020;emermed-2019-209077.

26. Harve-Rytsälä H, Ångerman S, Kirves H, Nurmi J. Arterial and end-tidal carbon dioxide partial pressure difference during prehospital anaesthesia in critically ill patients. Acta Anaesthesiol Scand [Internet]. Wiley; 2020 [cited 2020 Dec 11];aas.13751. Available from: https://onlinelibrary.wiley.com/doi/10.1111/aas.13751

27. Ogoh S. Interaction between the respiratory system and cerebral blood flow regulation [Internet]. J. Appl. Physiol. American Physiological Society; 2019 [cited 2021 Jan 11]. p. 1197-205. Available from: https://pubmed.ncbi.nIm.nih.gov/30920887/

28. Steiner LA, Balestreri M, Johnston AJ, Coles JP, Smielewski P, Pickard JD, et al. Predicting the response of intracranial pressure to moderate hyperventilation. Acta Neurochir (Wien) [Internet]. Acta Neurochir (Wien); 2005 [cited 2020 Dec 11];147:477-83. Available from: https://pubmed.ncbi.nlm.nih.gov/15770347/

29. NUNN JF, HILL DW. Respiratory dead space and arterial to end-tidal carbon dioxide tension difference in anesthetized man. J Appl Physiol [Internet]. 1960 [cited 2020 Dec 11];15:383-9. Available from: https://journals.physiology.org/doi/abs/10.1152/jappl.1960.15.3.383

30. Fiorentino M, Hwang F, Pentakota SR, Livingston DH, Mosenthal AC. Palliative Care in trauma: Not just for the dying. J Trauma Acute Care Surg [Internet]. Lippincott Williams and Wilkins; 2019 [cited 2020 Dec 11]. p. 1156-63. Available from: https://pubmed.ncbi.nlm.nih.gov/31658239/

\section{Tables}

\section{Table 1: Baseline characteristics of patients}




\begin{tabular}{|c|c|c|c|}
\hline \multirow[t]{2}{*}{ Variable } & Overall & Survivors & Non-survivors \\
\hline & $n=105$ & $n=77$ & $\mathrm{n}=28$ \\
\hline Age, years & $49.5 \pm 22.6$ & $43.4 \pm 21.0$ & $66.3 \pm 18.1$ \\
\hline Age $<18$ years, $n(\%)$ & $9(9)$ & $8(10)$ & $1(4)$ \\
\hline Male gender, $n(\%)$ & $71(68)$ & $51(66)$ & $20(71)$ \\
\hline ISS Total, median (IQR) & 25 (17 to 34$)$ & 25 (14 to 34$)$ & 31 (25 to 38 ) \\
\hline ISS $=75, n(\%)$ & $1(1)$ & 0 & $1(4)$ \\
\hline ISS Thorax, median (IQR) & 0 (0 to 2$)$ & 0 (0 to 2$)$ & 0 (0 to 2$)$ \\
\hline Missing (ISS Thorax), $n$ (\%) & $12(11)$ & $9(12)$ & $3(11)$ \\
\hline \multicolumn{4}{|l|}{ Cardiopulmonary parameters } \\
\hline Systolic BP, $m m H g$ & $127 \pm 33$ & $127 \pm 29$ & $125 \pm 43$ \\
\hline Diastolic BP, $m m H g$ & $78 \pm 28$ & $80 \pm 30$ & $72 \pm 21$ \\
\hline Pulse, $b p m$ & $93 \pm 26$ & $92 \pm 24$ & $93 \pm 32$ \\
\hline $\mathrm{SpO}_{2}$, median $(I Q R)$ & 100 (98 to 100$)$ & 100 (98 to 100$)$ & 99.5 (94.8 to 100$)$ \\
\hline Temperature, ${ }^{\circ} \mathrm{C}$ & $35.9 \pm 0.93$ & $35.9 \pm 0.93$ & $35.9 \pm 0.98$ \\
\hline Missing, $n(\%)$ & 16 & 11 & 5 \\
\hline \multicolumn{4}{|l|}{ Arterial blood gas } \\
\hline $\mathrm{pH}$, median (IQR) & 7.31 (7.26 to 7.35$)$ & 7.31 (7.28 to 7.36$)$ & 7.31 (7.19 to 7.33$)$ \\
\hline $\mathrm{BE}$, mmol/I median (IQR) & $-3.6(-6.4$ to -1.9$)$ & $-3.6(-5.8$ to -1.7$)$ & $-4.9(-8.4$ to -2.3$)$ \\
\hline $\mathrm{HCO}_{3}{ }^{-}$, mmol/I median (IQR) & 21.9 (19.9 to 23.6$)$ & 21.5 (20.5 to 23.6$)$ & 21.1 (19.6 to 23.4 ) \\
\hline Lactate, mmol/I median (IQR) & $2.0(1.2$ to 3.4$)$ & 1.9 (1.2 to 2.7$)$ & 2.8 (1.4 to 4.5$)$ \\
\hline $\mathrm{PaCO}_{2}, k P a$ median $(I Q R)^{*}$ & 6.0 (5.5 to 6.8$)$ & 5.9 (5.5 to 6.6$)$ & 6.4 (5.7 to 6.8$)$ \\
\hline $\mathrm{PaO}_{2}, k P a$ median $(I Q R)$ & 28.2 (17.6 to 48.9$)$ & 34.3 (19.6 to 51.5$)$ & 23.1 (14.9 to 29.8 ) \\
\hline Hemoglobin, $g / l$ & $122 \pm 21$ & $122 \pm 20$ & $119 \pm 24$ \\
\hline Glucose, mmol/I median (IQR) & $8.0(6.3$ to 10.1$)$ & 7.5 (6.0 to 8.9$)$ & 10.2 (8.1 to 13.2$)$ \\
\hline
\end{tabular}

Footnote: 
Data was complete if not otherwise specified. Continuous variables are reported as mean $\pm S D=$ (standard deviation) if normally distributed and not stated otherwise.

$\mathrm{BP}=$ blood pressure; IQR = Interquartile range; ISS = injury severity score; $\mathrm{bpm}=$ beats per minute; $\mathrm{SpO}_{2}=$ peripheral capillary oxygen saturation.

* $\mathrm{PaCO}_{2}=$ Same parameter as shown in detail on Table 2 (initial measure).

Table 2: $\mathrm{PaCO}_{2}$ and $\mathrm{EtCO}_{2}$ pairs at admission and after 24 hours

\begin{tabular}{|lllll|}
\hline Variable & $\begin{array}{l}\text { Overall } \\
\mathrm{n}=105\end{array}$ & $\begin{array}{l}\text { Survivors } \\
\mathrm{n}=77\end{array}$ & $\begin{array}{l}\text { Non-survivors } \\
\mathrm{n}=28\end{array}$ & p value \\
\hline Initial measures & $105(100)$ & $76(100)$ & $28(100)$ & \\
\hline $\mathrm{CO}_{2}$ gap, $\mathrm{kPa}$ & $1.64 \pm 1.09$ & $1.42 \pm 0.92$ & $2.26 \pm 1.30$ & $<0.001$ \\
\hline $\mathrm{PaCO}_{2}, \mathrm{kPa}$ & $6.26 \pm 1.03$ & $6.17 \pm 0.96$ & $6.48 \pm 1.18$ & \\
\hline $\mathrm{EtCO}_{2}, \mathrm{kPa}$ & $4.61 \pm 0.78$ & $4.76 \pm 0.74$ & $4.23 \pm 0.76$ & \\
\hline $\mathrm{PaCO}_{2}$ within 15 min of $\mathrm{EtCO}_{2}$ & $42(40)$ & $30(39)$ & $13(46)$ & \\
\hline $\mathrm{PaCO}_{2}$ within 30 min of $\mathrm{EtCO}_{2}$ & $60(57)$ & $39(51)$ & $21(75)$ & \\
\hline $\mathrm{Measures} \mathrm{within} \mathrm{24h}$ & $75(71)$ & $53(70)$ & $22(79)$ & \\
\hline $\mathrm{CO}_{2} \mathrm{gap}, \mathrm{kPa}$ & $0.64 \pm 0.82$ & $0.58 \pm 0.86$ & $0.78 \pm 0.70$ & 0.108 \\
\hline $\mathrm{PaCO}_{2}, \mathrm{kPa}$ & $5.12 \pm 0.60$ & $5.19 \pm 0.59$ & $4.91 \pm 0.58$ & \\
\hline $\mathrm{EtCO}_{2}, \mathrm{kPa}$ & $4.46 \pm 0.79$ & $4.59 \pm 0.82$ & $4.15 \pm 0.63$ & \\
\hline $\mathrm{Hours} \mathrm{since} \mathrm{admission}$ & $18.6 \pm 7.8$ & $19 \pm 8.0$ & $17.7 \pm 7.5$ & \\
\hline
\end{tabular}

\section{Footnote:}

Data was complete. Numbers are presented with percentages of total in parentheses. Continuous variables are reported as mean $\pm \mathrm{SD}$ (standard deviation). The $\mathrm{CO}_{2}$ gap and the $\mathrm{PaCO}_{2}$ variables were skewed; however, the mean \pm SD was presented due to the use of these parameters in the Bland-Altman plots. $\mathrm{CO}_{2}$ gap $=\mathrm{PaO}_{2}-\mathrm{EtCO}_{2}$ 
Table 3: Multivariate logistic regression model of survival

\begin{tabular}{|lllll|}
\hline Variable & Odds Ratio & $\mathbf{9 5 \%}$ Cl of OR & Standard error & p value \\
\hline $\mathrm{CO}_{2}$ gap, $\mathrm{kPa}$ & 2.692 & 1.283 to 5.646 & 0.385 & 0.009 \\
\hline Age, 10 years & 1.063 & 1.026 to 1.102 & 0.018 & 0.001 \\
\hline Systolic $\mathrm{BP}, \mathrm{mmHg}$ & 1.002 & 0.986 to 1.018 & 0.008 & 0.822 \\
\hline Pulse, $b p m$ & 0.984 & 0.960 to 1.009 & 0.013 & 0.199 \\
\hline $\mathrm{SpO}_{2}, \%$ & 0.960 & 0.810 to 1.137 & 0.106 & 0.635 \\
\hline $\mathrm{PaO}_{2}, \mathrm{KPa}$ & 0.966 & 0.926 to 1.007 & 0.022 & 0.101 \\
\hline $\mathrm{ISS}_{\mathrm{SS}} \mathrm{Thorax}$ & 1.030 & 0.683 to 1.554 & 0.214 & 0.887 \\
\hline
\end{tabular}

\section{Footnote:}

Complete case analysis available for 93 patients. Twelve patients were excluded from the analysis due to missing data (see Table 1). Units of measure and abbreviations as described in Tables 1 and 2.

\section{Figures}




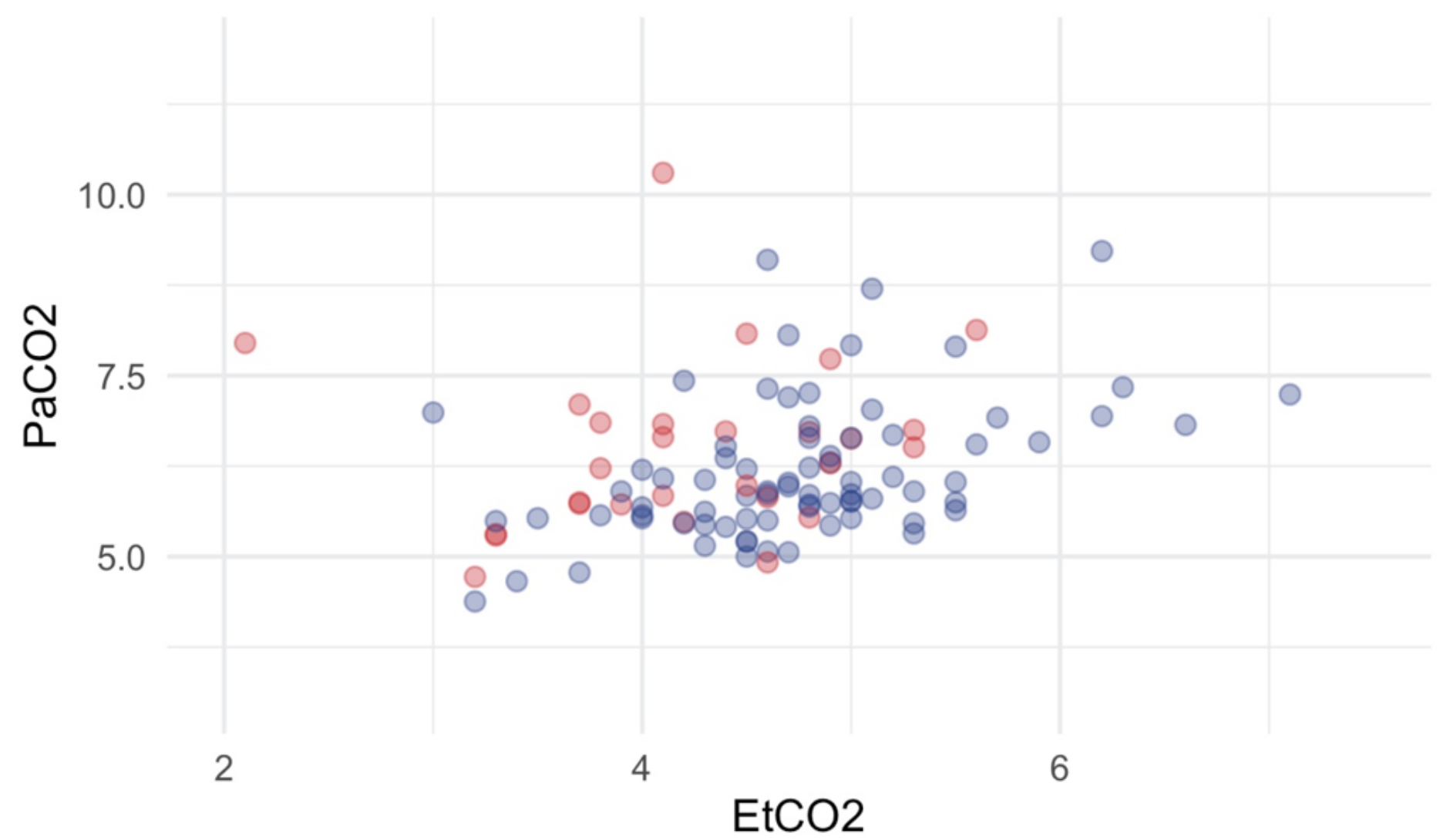

Outcome $\odot$ Alive $\bigcirc$ Dead

Figure 1

Correlation of PaCO2 and EtCO2. Footnote: Pearson's correlation coefficient overall $r=0.287$, for survivors $r=0.438$, for non-survivors $r=0.150 . P a C O 2$ and EtCO2 in $\mathrm{kPa}$ 

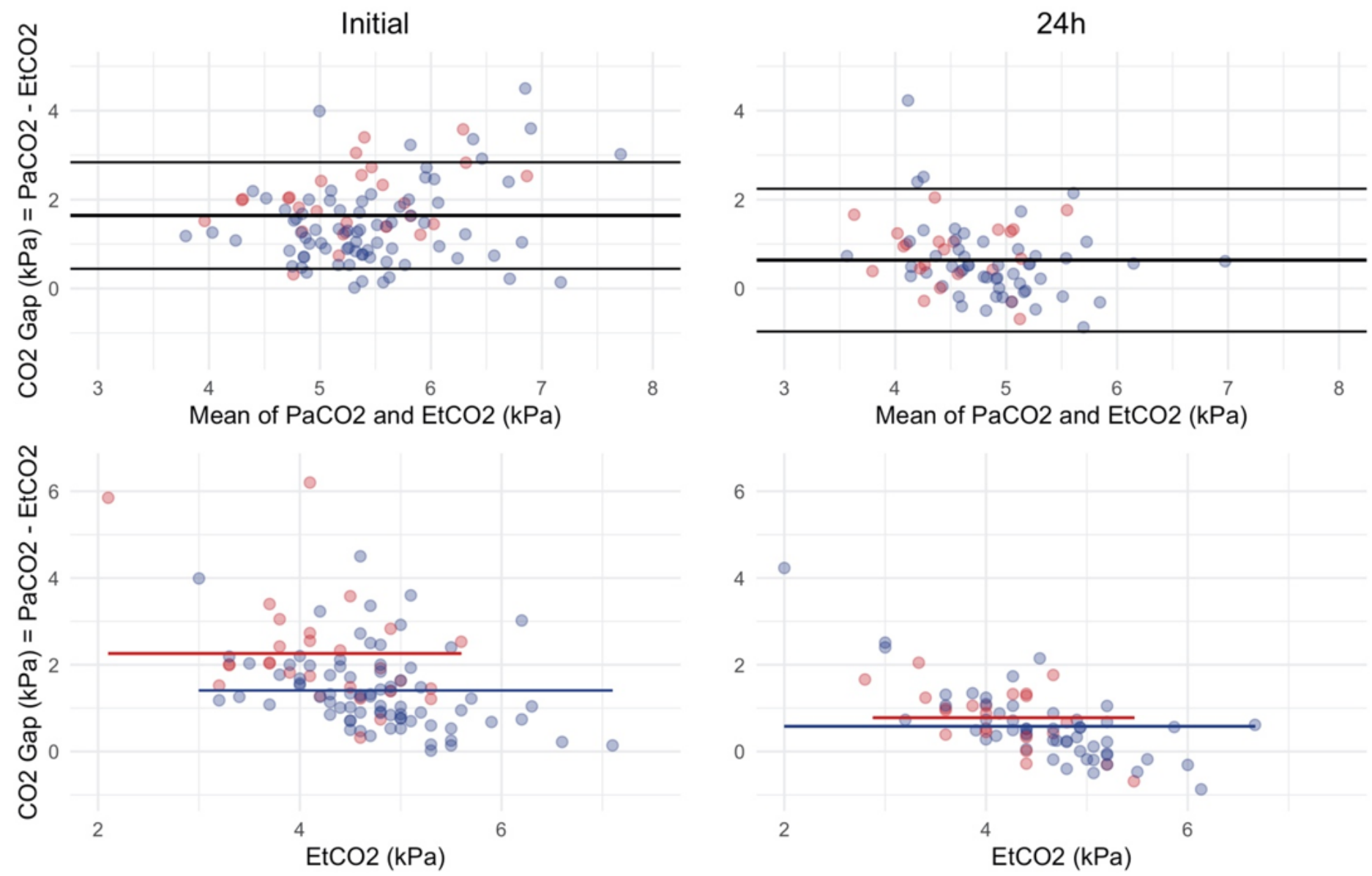

Outcome Alive Dead

\section{Figure 2}

Bland-Altman plots and point plots comparing PaCO2 and EtCO2. Footnote: Top row: Bland-Altman plots for all available pairs of $\mathrm{PaCO} 2$ and $\mathrm{EtCO} 2$ at different time points. Bottom row: corresponding point plots for the same data. The red and blue lines illustrate the mean $\mathrm{CO} 2$ gap for deceased and surviving patients, respectively. The mean $\mathrm{CO} 2$ gap lines are trimmed, illustrating the EtCO2 range for both groups, respectively. Difference between $\mathrm{PaCO} 2$ and EtCO2 was highly significant for the initial pairs $(p<0.001)$ but not for the pairs after 24 hours (see Table 2). 


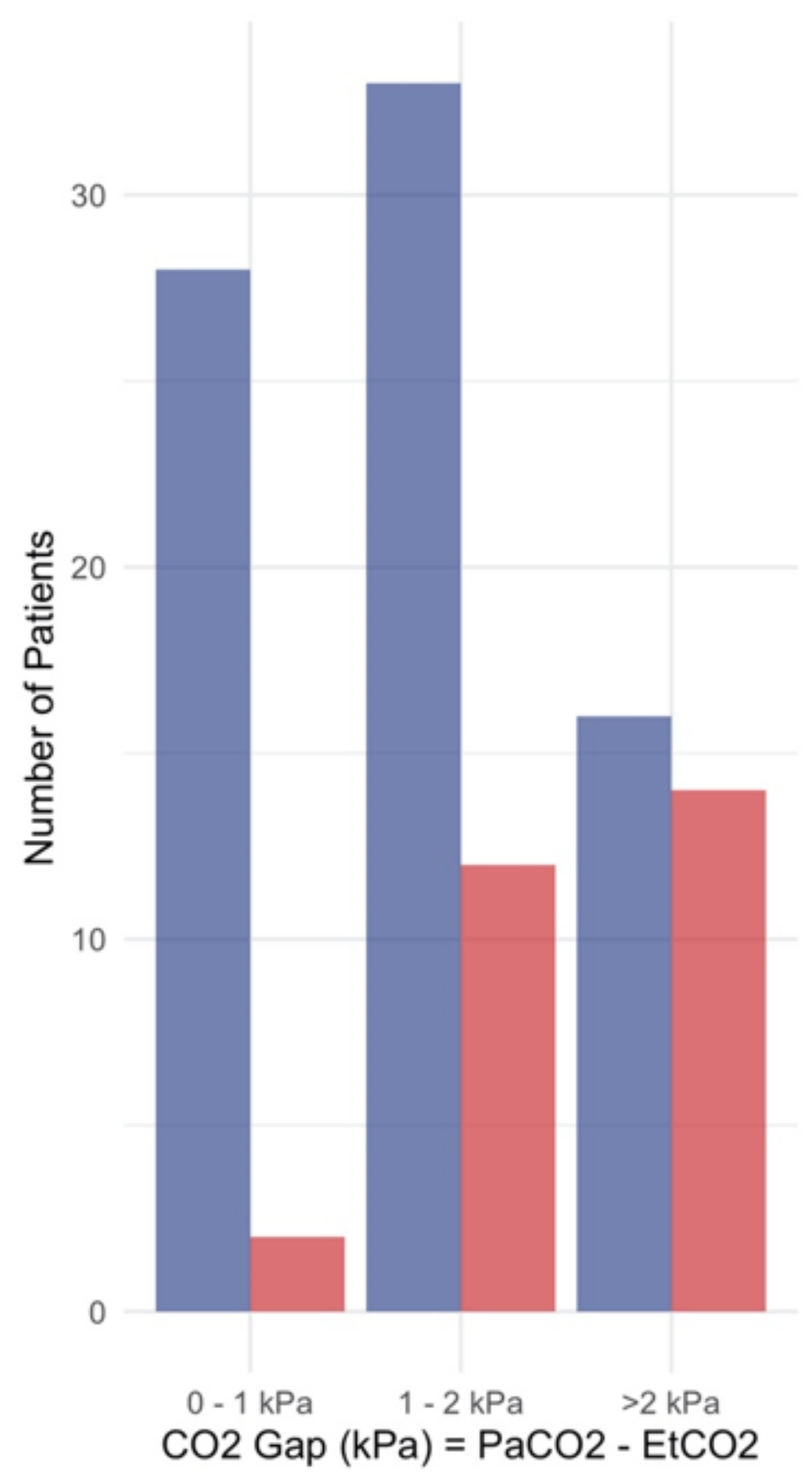

Outcome Alive Dead

Figure 3

Bar diagram showing survival for $\mathrm{CO} 2$ gap groups. Footnote: Bar diagram showing outcome by groups of CO2 gap measured initially. 
CO2 Gap

Age

Systolic Blood Pressure

Heart Rate

$\mathrm{SpO} 2$

$\mathrm{PaO} 2$

ISS Thorax

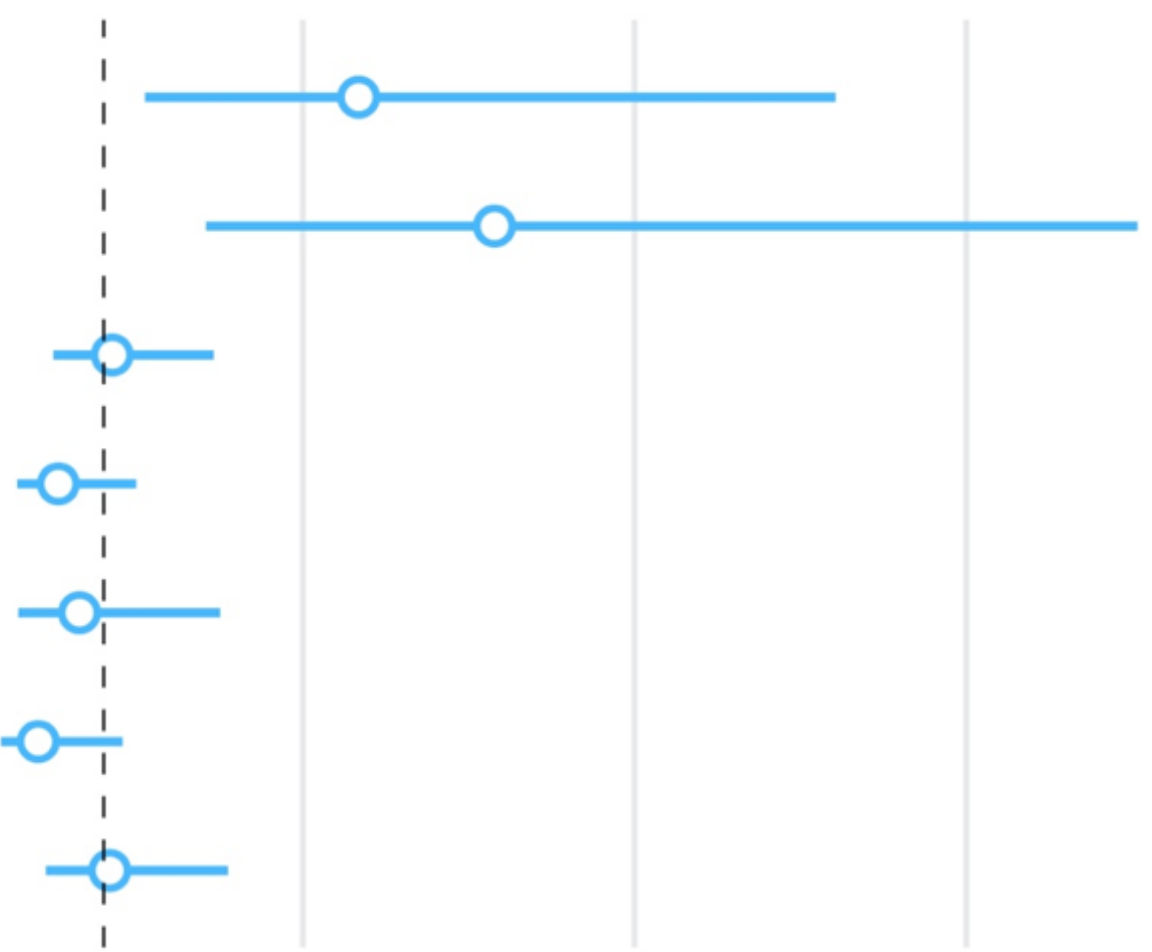

2.5
7.5

\section{Odds Ratio}

\section{Figure 4}

Scaled regression coefficient of the multivariate logistic regression. Footnote: Illustration of the multivariate logistic regression model summarized on Table 3. Regression coefficients are exponentiated and scaled. The horizontal lines around the dots indicates the $95 \%$ confidence interval of the odds ratio. $\mathrm{CO} 2$ gap $=\mathrm{PaO} 2-\mathrm{EtCO} 2$. 